\title{
A EXPERIÊNCIA DE PAIS PARTICIPANTES DE UM GRUPO DE EDUCAÇÃO PARA SAÚDE NO PRÉ-NATAL
}

\author{
THE EXPERIENCE OF FATHERS PARTICIPANTS OF HEALTH \\ EDUCATION GROUP IN PRENATAL CARE
}

\section{LA EXPERIENCIA DE PADRES PARTICIPANTES DE UN GRUPO DE EDUCACIÓN EN SALUD EN LA ATENCIÓN PRENATAL}

\author{
Luciana Magnoni Reberte* \\ Luiza Akiko Komura Hoga ${ }^{*}$
}

\begin{abstract}
RESUMO
Esta pesquisa teve o objetivo de descrever a experiência de pais que participaram em um grupo de educação para a saúde realizado na assistência pré-natal. O grupo foi desenvolvido mediante a estratégia da pesquisa-ação em um Hospital Universitário da cidade de São Paulo, Brasil e contou com a participação de oito gestantes e quatro maridos. Das entrevistas individuais feitas com os maridos, integralmente gravadas, transcritas e analisadas de forma indutiva e interpretativa, emergiram três categorias descritivas: a) A participação no grupo permitiu compartilhar das experiências de forma mais intensa, b) a participação no grupo permitiu melhor compreensão da mulher grávida e promoveu a qualidade do suporte oferecido a ela, c) o aprendizado e o desenvolvimento das técnicas corporais promoveram a integração do casal e entre os participantes no grupo. A participação ativa do pai nas atividades educativas da assistência pré-natal deve ser incentivada porque este medida produz benefícios para ele e, conseqüentemente, para sua família e a sociedade.
\end{abstract}

Palavras chave: Gravidez, educação em saúde, paternidade, cuidado pré-natal.

\begin{abstract}
The aim of this research was to describe the experience of fathers, participating in a health education group during prenatal care. An action research strategy was adopted to carry out the study and handle the group, at a University Hospital, city of São Paulo, Brazil. The group was conformed by eight pregnant women and four husbands. From the individual interviews carried out with the husbands, fully recorded, transcribed and analyzed in an inductive and interpretive way, three descriptive categories emerged from the experience: a) The participation in the group permitted to share the experiences in a more intensive way, b) the participation in the group permitted a better understanding of the pregnant woman and promoted the quality of support offered to her, c) the knowledge and the development of body techniques promoted the integration of the couples and among the participants of the group. The fathers' active participation in the educational activities carried out in prenatal care should be encouraged to produce benefits for him and, consequently, to his family and the society.
\end{abstract}

Key words: Pregnancy, health education, paternity, prenatal care.

\footnotetext{
* Enfermeira obstetra. Aluna do curso de doutorado do Programa de Pós-Graduação em Enfermagem. Escola de Enfermagem da Universidade de São Paulo. São Paulo, Brazil. E-mail: lu.mare@ig.com.br

${ }_{* *}^{*}$ Enfermeira obstetra. Professora Associada do Departamento de Enfermagem Materno-Infantil e Psiquiátrica da Escola de Enfermagem da Universidade de São Paulo. São Paulo, Brazil. E-mail:kikatuca@usp.br
} 


\section{RESUMEN}

Esta investigación tuvo el objetivo de describir la experiencia de padres que habían participado de un grupo de educación en salud realizado en la atención prenatal. El grupo fue desarrollado con empleo de la metodología de investigación-acción en el Hospital Universitario de la ciudad de São Paulo, Brasil y tuvo la participación de ocho embarazadas y cuatro acompañantes. De las entrevistas individuales hechas con los maridos, las que fueron completamente grabadas, transcritas y analizadas de forma inductiva e interpretativa, surgieron tres categorías descriptivas: a) La participación en el grupo permitió compartir las experiencias de forma más intensa, b) la participación en el grupo permitió mejorar la comprensión de la mujer embarazada y promovió la calidad en el soporte ofrecido a ella, c) el aprendizaje y el desarrollo de las técnicas corporales promovió la integración entre las parejas y entre los participantes del grupo. La participación activa de los padres en las actividades educativas del cuidado prenatal debe ser incentivada, pues esta medida produce beneficios para él y, consecuentemente, a su familia y la sociedad.

Palabras clave: Embarazo, educación en salud, paternidad, atención prenatal.

Fecha recepción: 07/07/08 Fecha aceptación:15/12/09

\section{INTRODUÇÃO}

A promoção do maior envolvimento masculino na saúde sexual, reprodutiva e da mulher foi uma das recomendações constantes no documento produzido por especialistas participantes da Conferência Internacional de População e Desenvolvimento, ocorrido na cidade do Cairo em 1994 (1). Esta recomendação impulsionou a formulação de políticas públicas e o desenvolvimento de projetos com a finalidade de promover a participação dos homens nos vários âmbitos da assistência à saúde da mulher. Este fato pode ser observado nas publicações científicas que fazem referência a projetos desta natureza.

Desde então, a presença masculina nos cenários de assistência à saúde da mulher apresentou um crescente aumento, mas ainda não constitui uma realidade sedimentada. Verifica-se que as atividades deste âmbito permanecem com o enfoque voltado ao atendimento das necessidades das mulheres. Presume-se que esta realidade decorre do fato dos homens ainda não estarem incluídos, de forma sistemática, nas atividades de assistência à saúde da mulher $(2,3)$. Quando os homens estão presentes, a atenção que é destinada a eles é insuficiente. No caso dos grupos educativos desenvolvidos na assistência pré-natal, em geral, os pais são treinados apenas para oferecer suporte à mulher no parto e colaborar com a equipe de saúde (4, $5)$.

Mas, na realidade, eles requerem maior atenção, pois vivenciam a ansiedade, preocupação, nervosismo e insegurança quando suas esposas estão grávidas ou no período pós-parto. Sentimentos que se manifestam de forma amena no início da gestação e se intensificam com a proximidade do parto e as pessoas que os vivenciam requerem suporte profissional. Este pode ser oferecido mediante o desenvolvimento de programas educativos voltados à promoção de uma vivência mais significativa e construtiva dos papéis de marido e pai (6).

A participação em grupo educativo no pré-natal proporciona um envolvimento ativo dos homens com a gravidez. Isto porque o entendimento das alterações que ocorrem durante o ciclo gravídico e puerperal produz reflexos positivos sobre a relação marital e a dinâmica familiar. Os diálogos a respeito das questões que afetam o casal nesta fase da vida surgem com maior freqüência e naturalidade, e eles passam a ser discutidas com base em fundamentos apropriados. Dessa forma, as pessoas envolvidas são favorecidas porque 
encontram circunstâncias mais adequadas para vivenciar este período, de forma consciente e construtiva (7).

Há comprovação de que as gestantes, cujos parceiros participam das atividades de educação para a saúde no pré-natal, apresentaram comportamentos melhores em relação ao cuidado com a saúde se comparadas àquelas que não puderam contar com esta adesão. As diferenças foram significativas especialmente no que se referiram aos cuidados realizados durante o período pós-parto (8).

Os fundamentos apresentados são suficientes para recomendar a inclusão dos homens nas atividades de educação para a saúde da mulher. Apesar disto, a presença masculina não se configura ainda como uma realidade sedimentada nestes cenários assistenciais tendo em vista que, em muitos deles, os homens ainda permanecem excluídos (9).

Ao desenvolver atividades educativas junto a grupos de gestantes é importante conhecer as expectativas e necessidades do conjunto de seus integrantes, inclusive os maridos, pois este saber é essencial para que as atividades atendam as demandas de todos (10). Considerou-se que muitos investimentos ainda precisam ser realizados para melhorar a qualidade nesta esfera da assistência. Impulsionados por esta crença, os responsáveis por esta pesquisa desenvolveram grupos educativos com gestantes, com a presença e participação ativa de seus maridos.

Acreditou-se que o conhecimento sistematizado das experiências vividas por estes maridos permitiria reconhecer suas reais demandas e aperfeiçoar as atividades de educação para a saúde na gestação a serem realizadas no futuro. Ao revisar a literatura percebeu-se a necessidade de mais dados a este respeito, o que motivou a realização desta pesquisa.

Seu objetivo foi descrever a experiência de pais que participaram de um grupo de educação para a saúde na assistência pré-natal.

\section{MATERIAL E MÉTODO}

O grupo foi desenvolvido no ambulatório de um Hospital Universitário localizado na cidade de São Paulo, Brasil. Esta instituição, que é governamental e oferece atendimento gratuito, atende moradores de sua área de abrangência conforme o estabelecido pelo Sistema Único de Saúde (SUS). Também oferece assistência à comunidade universitária, composta por estudantes, docentes e funcionários não-docentes da Universidade.

As atividades de educação em saúde com os integrantes dos grupos de gestantes são da responsabilidade de enfermeiras obstétricas e todas as gestantes que fazem acompanhamento pré-natal na instituição são convidadas a participar. Esta atividade é oferecida regulamente e constitui um recurso conhecido pelos usuários do hospital.

Neste artigo, são apresentados dados referentes a um grupo específico desenvolvido por uma docente e uma aluna da Escola de Enfermagem da Universidade de São Paulo. Oito gestantes e quatro maridos participaram espontaneamente do grupo. Quatro delas, que não puderam contar com a presença dos maridos, justificaram que a ausência deles era devida à falta de disponibilidade ou interesse em participar.

A diferença deste grupo em relação ao que é habitualmente realizado na instituição foi o fato de ter sido adotada a estratégia da pesquisa-ação para o seu desenvolvimento e terem sido incluídas técnicas corporais em todas as sessões realizadas. A pesquisa-ação, que se caracteriza pelo predomínio da natureza exploratória em todas as suas etapas, pressupõe a associação da ação com a atividade de pesquisa e esta união deve beneficiar as pessoas envolvidas (11). Com base nos pressupostos da pesquisa-ação, foram realizadas as sessões grupais de educação em saúde durante a gestação. Na primeira sessão, todos os integrantes do grupo foram estimulados a expressar suas demandas e explicitar os con- 
teúdos que gostariam de aprender e discutir nas sessões subsequentes.

Esta estratégia permitiu a abordagem de conteúdos específicos, em conformidade com a demanda e o interesse do conjunto de integrantes do grupo. Desse modo, todos puderam participar, em maior ou menor intensidade, das decisões tomadas em grupo e dar direcionamento às sessões subsequentes. A percepção dos participantes, relativa ao emprego desta estratégia no desenvolvimento de atividades em grupo no pré-natal, está descrita em outra publicação (12). Em suma, os participantes expressaram sentimentos de satisfação em relação ao emprego da metodologia de pesquisa-ação no desenvolvimento do grupo.

A estratégia participativa permitiu delinear os conteúdos a serem trabalhados nas sessões subseqüentes e a possibilidade de determinar a periodicidade e a duração dos encontros grupais também foi oferecida. Decidiu-se que as sessões seriam semanais, com duração de duas horas e houve consenso de que seriam realizadas sessões em quantidade suficiente para garantir a abordagem de todos os conteúdos requeridos, totalizando 9 encontros. Também foi decidido que haveria a inclusão de trabalhos corporais.

Os temas requeridos e desenvolvidos nas sessões grupais, de forma resumida, foram os relativos às transformações físicas, emocionais e no âmbito das relações familiares e sociais que ocorrem durante a gravidez, o parto, o puerpério e os decorrentes da chegada de um novo integrante na família. Orientações a respeito dos cuidados necessários para uma vivência mais plena de todo o processo, dos pontos de vista da gestante, seu marido e demais membros da família também foram fornecidas e discutidas. Estes conteúdos foram trabalhados por meio da exposição dialogada. As dúvidas que surgiam no decorrer dos trabalhos eram sanadas.

$\mathrm{Na}$ seqüência, eram realizados os trabalhos corporais. Primeiramente, era feita a demonstração de uma técnica, seguida pela aplicação da técnica feita na gestante pelo marido, que depois retribuía-na, desenvolvendo o recurso junto ao seu marido. Na falta deste, as trocas foram feitas entre as gestantes desacompanhadas. As técnicas corporais desenvolvidas foram: a massagem de deslizamento manual nos membros inferiores, no sentido caudal para o cefálico; promoção de relaxamento e percepção corporal; identificação de segmentos corporais tensos e realização de massagem mediante a utilização de bolas de tênis, por meio de movimentos circulares; balanceio pélvico; técnica de contração de todos os segmentos corporais, com ênfase na contração da musculatura pélvica seguida de relaxamento, técnicas de respiração torácica e abdominal; massagem de deslizamento com emprego do bambu; massagem do tipo fricção sobre as proeminências ósseas da região lombar e massagem para bebês por meio da aplicação dos princípios da bioenergética suave.

Cada técnica corporal realizada tinha seu objetivo e, em suma, estes recursos tinham o propósito de reduzir a sensação dolorosa no corpo, prevenir insônia, diminuir fadiga corporal e promover consciência corporal, reduzir os desconfortos provocados pelo volume abdominal, favorecer a consciência do estado de relaxamento, promover o conhecimento e adoção dos tipos de respiração adequados durante as etapas do trabalho de parto e parto e diminuir tensões musculares.

$\mathrm{Na}$ etapa de coleta de dados, informações a respeito da experiência dos maridos foram obtidas mediante entrevistas individuais gravadas. Após a finalização do grupo, foi feito um contato telefônico com cada marido, para agendar uma entrevista, com data, local e horário da preferência e disponibilidade de cada um. Eles deram preferência ao próprio domicílio ou às dependências da instituição (2) para conceder as entrevistas. A seguinte questão introdutória, para facilitar a descrição da experiência foi feita no início de cada entrevista: "Fale-se a respeito de sua experiência de ter participado do grupo de educa- 
ção e promoção da saúde" (13).

As entrevistas, gravadas na íntegra, foram literalmente transcritas. Elas foram atentamente lidas e identificaram-se as principais representações a respeito da experiência. A análise dos dados foi feita mediante um processo indutivo e interpretativo, que permitiu obter uma noção do que era típico em relação ao fenômeno estudado (14).

Os principais significados contidos nos parágrafos e no conjunto de cada entrevista foram identificados e, de acordo com a similaridade temática, foi atribuída uma pré-codificação. Este procedimento, realizado com todas as entrevistas, permitiu elaborar categorias descritivas da experiência, tal como preconizado na análise de dados qualitativos (13-15).

Pequenos trechos extraídos das narrativas foram utilizados para exemplificar os conteúdos e significados apresentados nas categorias descritivas. Cada pequeno trecho foi separado por pontos (...) de modo a sinalizar que cada parte foi extraída da narrativa de uma determinada pessoa, que foi identificada neste artigo por meio de um número. Este recurso foi utilizado para tornar a descrição da experiência mais próxima da realidade e preservar a perspectiva individual. Por meio dele, buscou-se resgatar e preservar as experiências pessoais e propiciar a sensação de proximidade em relação a cada um dos maridos. Permitiu também conferir fidedignidade aos dados e atribuir rigor a esta pesquisa qualitativa, tal como o recomendado por eminentes pesquisadores desta abordagem metodológica (16).

Os aspectos éticos da pesquisa foram obedecidos. O projeto foi aprovado pelo Comitê de Ética em Pesquisa da Instituição, que é credenciado no Conselho Nacional de Ética em Pesquisa do Brasil. Foram dados esclarecimentos a respeito da atividade de pesquisa associada à ação educativa e todos os participantes do grupo assinaram o Termo de Consentimento Livre e Esclarecido. Nele, estavam explicitados os direitos e deveres dos participantes do grupo, inclusive a garantia do anonimato e a preservação e respeito às características individuais e do caráter confidencial dos assuntos discutidos nas sessões grupais.

\section{RESULTADOS E DISCUSSÃO}

\section{As características pessoais dos maridos}

A idade dos maridos variou entre 37 e 43 anos e a escolaridade, de um deles era ensino médio completo (oito anos de estudo) e dos outros três era universitário completo (15 ou mais anos de estudo). Eles exerciam as funções de engenheiro, professor universitário, trabalhador autônomo e arquiteto. Em relação ao número de filhos, um já tinha tido um filho e três iam se tornar pais pela primeira vez.

Os resultados desta pesquisa apontaram alguns aspectos importantes que merecem a atenção dos profissionais que atuam nesta área.

\section{Categorias descritivas da experiência de participar nos grupos educativos}

\section{a) A participação no grupo permitiu com- partilhar experiências de forma mais in- tensa}

Participar no grupo contribuiu para que os maridos tenham tido a possibilidade de compartilhar das experiências vivenciadas pelas esposas, de forma mais intensa. Isto foi possível mediante o oferecimento de suporte e auxílio a elas em relação a vários aspectos relacionados à gravidez, entre eles, o alívio aos desconfortos corporais e a contribuição na diminuição da ansiedade em relação ao parto.

O que me motivou foi saber que poderia ajudar em uma coisa no corpo dela, aliviar nos desconfortos (1); Eu não posso ficar grávi- 
do, mas minha idéia sempre foi participar (2); Eu participei do curso para aprender, motivar minha mulher e principalmente para ela ficar mais sossegada, porque ela tem medo do parto (3).

Este sentimento reforça a importância do pai entrar em contato com as sensações corporais femininas e com os conteúdos relacionados ao trabalho de parto desde a gestação (17). Assim como a presente pesquisa, outros estudos mostraram que os homens possuem preocupações com suas mulheres grávidas e desejam fornecer suporte a elas ${ }^{1}$ (18).

Estar presente e participar ativamente das atividades realizadas em grupo permitiu compartilhar as experiências tidas por outros integrantes do grupo. Isto possibilitou constatar que os demais homens vivenciavam situações que eram semelhantes às suas. Ao mesmo tempo, puderam perceber que as pessoas atribuem significados às experiências que vivenciam de modo específico, e que isto é influenciado pela bagagem cultural e pessoal. $\mathrm{O}$ contato com estas semelhanças e diferenças fez com que os maridos tenham adquirido uma compreensão mais ampla dos integrantes do grupo e das pessoas em geral.

... eu achei muito bom trocar experiências com as pessoas, ver que cada pessoa tem sua individualidade, ver que uma gestante sente uma coisa e outra sente coisa parecida, que uma terceira não sente (3)... esta troca de informações e experiências foi boa, amadureceu, fez a gente compreender melhor as pessoas (2)

As sensações de afinidade, reciprocidade e empatia em relação aos demais integrantes do grupo emergiram durante o processo de interação proporcionada pela participação no grupo e isto foi visto como um aspecto positivo.

Encontrei pessoas legais, trocamos idéias boas (4)... durante as sessões, pudemos conhecer melhor o outro, se colocar no lugar do outro, quando nascia a criança, um telefonava para o outro, avisando, fizemos amizades, foi muito bom este aspecto (3).

Os maridos, que participaram ativamente nos trabalhos grupais, puderam compartilhar experiências e constataram que outros homens vivenciam situações semelhantes, e isto promoveu a qualidade do relacionamento entre o casal e envolvimento com a gravidez e o papel paterno. A possibilidade que os homens tiveram, de refletir a respeito destas questões, contribuiu no aprofundamento das relações entre os próprios casais e destes com os demais participantes do grupo, produzindo reflexos positivos para todos os participantes.

Estes fatos comprovaram que a inserção do homem em espaços destinados à compreensão de si e dos outros, de novos papéis sociais, como aqueles que dizem respeito ao ser mãe e ser pai, influenciam positivamente suas experiências, especialmente no que se refere à vivência mais consciente e plena de seus papéis. São fatos que justificam a importância da proposição de políticas públicas e ações permanentes desta natureza nas instituições de saúde $(4,19)$.

\section{b) A participação no grupo permitiu me- lhor compreensão da mulher grávida e pro- moveu a qualidade do suporte oferecido a ela}

Compreender, com maior profundidade e abrangência, os fenômenos que são próprios à gravidez, sobretudo os fundamentos fisiológicos do surgimento dos diferentes sinais e sintomas orgânicos, contribuiu para a manutenção da tranqüilidade em relação a eles e o envolvendo mais profundo com o conjunto do processo. Os maridos, que puderam constatar que as demais mulheres tinham sinais e sintomas semelhantes às apresentadas pelas suas, puderam manter a calma em relação às ocorrências próprias da gravidez. O senti- 
mento de satisfação em relação a estes aspectos foi expresso por todos os maridos e isto os impulsionou a recomendar a participação de outros pais nos grupos educativos oferecidos nos serviços de assistência pré-natal.

Eu tinha noção de que as coisas são normais, mas foi bom ouvir isso do grupo, de vocês... dou este exemplo para encorajar as pessoas a fazerem o curso na gravidez... (2, 3)... achei legal, superou as expectativas ... para nós que somos leigos no assunto, esclareceu muita coisa. $(1,2)$, gostei do bebezinho que mostrava cada semana do desenvolvimento, como vai crescer, como vai se formando a criança, como vai se colocando no lugar para nascer (3), foi boa a preparação das mamas (4), a parte de parto natural foi bacana, a explicação sobre o fórcipe também foi essencial (2).

É fundamental que os homens tenham facilidade para acessar estes serviços, sintam-se acolhidos nos grupos educativos, continuem motivados a participar e tenham justificativas concretas para sugerir que outros pais também participem (20).

A compreensão dos fundamentos que acarretam as alterações emocionais que afetam as gestantes foi considerado como um aspecto positivo porque aumentou a capacidade de percepção das demandas das esposas. Esta condição proporcionou a sensação de segurança e promoveu a capacidade de oferecer apoio, com prontidão e de acordo com as necessidades percebidas.

Tinha coisas que eu não entendia direito, tem homem que acha que a mulher grávida é chata, mas é muita transformação no corpo, nos hormônios, altera o humor e outras coisas, com o que aprendi no grupo consegui superar isto (2) você compreende melhor as transformações que acontecem nas gestantes e a sua razão e isto ajudou muito (1), o curso deu estabilidade e segurança porque a gente fica sabendo o que pode acontecer e consegue ficar mais seguro para dar um passo sem medo de fazer besteira (4).

Este conjunto de fatores, que foi considerado como produto da participação no grupo, proporcionou o envolvimento mais profundo dos maridos com a gravidez e a paternidade.

Com relação à paternidade, acho que participar do grupo, que ocorre antes do nascimento ajudou a me aproximou mais da minha mulher e do bebê, aumentou o envolvimento, até o fato de irmos juntos lá e discutir os assuntos, muita coisa a gente chegava em casa e ainda conversava a respeito (1), acho que o curso ajudou a ver que a questão não é se concentrar na mulher, é se concentrar também no filho que a mulher carrega (3), por mais que você esteja sexualmente distante por certa confusão corporal que ela esta passando, você pode ficar fisicamente próximo, com carinho, e se concentrar nos projetos do bebê (2).

Os maridos puderam constatar que a participação no grupo proporcionou o atendimento às suas próprias questões referentes ao relacionamento conjugal e à transição para a paternidade pela melhor compreensão da mulher e envolvimento com a gravidez. Por isso, possibilitar condições apropriadas para que o homem possa atuar como agente ativo do processo requer a atenção dos profissionais, na mesma intensidade e proporção destinada à mulher $(21,22)$.

\section{c) $\mathrm{O}$ aprendizado e o desenvolvimento das técnicas corporais promoveram a integra- ção do casal e entre os participantes no grupo}

O aprendizado das técnicas corporais permitiu aos maridos realizar este tipo de atividade com suas esposas e isto contribuiu para o alívio dos desconfortos referidos por elas. A realização destas práticas proporcionou a participação ativa na gravidez e promoveu a integração mais profunda entre os casais.

A gente não pode interferir muito, mas eu me senti mais participativo, todo dia eu fazia massagens, principalmente porque ela falava que estava inchada. Ela não teve muito problema com isso porque eu ajudei bastante (1), a mulher anda, fica inchada e pode ter varizes, 
tem que fazer massagens para não ter varizes, para a mulher ficar com as pernas bonitas, a respiração adequada na hora do parto, para ter o bebe de parto normal, isso tudo eu guardei e ajudei na hora do parto (3).

Alguns homens mencionaram a prática de técnicas de alívio dos desconfortos corporais antes da participação no grupo. Até mesmo estes se interessaram no aprendizado de novas técnicas e as desenvolveram junto às suas esposas. Eles constataram que estas trocas de massagens proporcionaram prazer corporal e aproximou mais os casais e este conjunto beneficiou os envolvidos neste processo.

Eu já fazia massagens, mas aprender outras técnicas foi bom, minha esposa adorou e eu me senti bem, flutuando, relaxado (3), você proporcionar prazer físico para alguém quebra a barreira, aproxima, por isso foi bom (2).

$\mathrm{O}$ aprendizado e o conseqüente desenvolvimento de técnicas corporais junto às esposas promoveram a participação ativa dos maridos no processo gestacional e um envolvimento mais profundo entre os casais e destes com os demais participantes. Portanto, a inclusão desta estratégia no desenvolvimento de grupos de educação e promoção da saúde da gestante deve ser incentivada, pois existem avaliações positivas deste recurso, que é considerado efetivo para contemplar necessidades de gestantes e de seus maridos ${ }^{2}(23)$.

\section{CONCLUSÃO}

Os resultados desta pesquisa servem como incentivo à incorporação, de forma sistemática, dos homens na assistência às fases do curso de vida familiar e isto contribuirá para a transformação dos modelos de atenção vigentes nos cenários de atenção à saúde.
A inclusão dos membros da família, como personagens ativos do cuidado nos processos que lhes são inerentes, contribuirá para o fortalecimento da própria família, que se torna mais capacitada para cuidar de suas questões ${ }^{3}$.

A falta de disponibilidade e de interesse mencionadas pelas gestantes, na presente pesquisa, como obstáculos à participação dos maridos nas atividades educativas indicaram a necessidade de facilitar, tanto quanto possível, o acesso a este tipo de atividade. O desenvolvimento de trabalhos desta natureza, na própria comunidade e mediante a colaboração de agentes comunitários de saúde, pode constituir uma forma de solucionar o problema de homens que não dispõem de flexibilidade nas suas atividades laborais e, por meio desta estratégia, facilitar a participação (24).

É primordial que os gestores da assistência à saúde e os profissionais responsáveis por oferecer este tipo de atividade considerem as condições de vida e de trabalho das pessoas no mundo atual. Esta é caracterizada pela concorrência, necessidade de grande produtividade e conseqüente dificuldade para se ausentar do trabalho, sobretudo em se tratando de liberação para participar de atividades relacionadas à educação em saúde. Este problema demanda a necessidade de diversificar e tornar mais flexíveis os horários de oferecimento destas atividades, assim como os dias da semana, com o intuito de facilitar o acesso e a freqüência a elas.

O envolvimento e participação ativa dos homens em todos os aspectos relacionados à saúde da mulher são incontestavelmente relevantes. Salienta-se, entretanto, que este tipo de trabalho não deve ser proposto com objetivos restritos ao atendimento das necessidades das mulheres. Homens e

\footnotetext{
${ }^{2}$ Nakano AMS. Os métodos psicossomáticos de preparação para o parto: análise de seus objetivos e finalidades [Dissertação de Mestrado]. Ribeirão Preto, São Paulo: Escola de Enfermagem de Ribeirão Preto. Universidade de São Paulo; 1990.

${ }^{3}$ Pettengill MAM. Vulnerabilidade de família: desenvolvimento do conceito. [Tese de Doutorado]. São Paulo: Escola de Enfermagem. Universidade de São Paulo; 2003.
} 
mulheres apresentam demandas distintas e próprias, e este fato precisa ser reconhecido pelos profissionais. O reconhecimento das necessidades masculinas e a chance de discutir as ansiedades, especialmente relativas à definição do papel paterno, nas atividades educativas no pré-natal podem proporcionar ao homem uma transição mais suave para a paternidade (5).

Acredita-se que, por meio do conjunto de ações recomendadas neste artigo, as famílias poderão tomar suas decisões de forma mais coesa e com base em fundamentos mais sólidos e apropriados.

Esta pesquisa teve a limitação de ter uma amostra muito pequena, pois contou com a participação de apenas quatro homens no grupo educativo no pré-natal. Considerouse, entretanto, que a riqueza de seus depoimentos abrangeu amplos aspectos do tema sob estudo. O conjunto do trabalho foi realizado pelos autores deste artigo. Por este motivo os maridos tinham ciência de que as pesquisadoras não faziam parte do quadro de profissionais do hospital e poderiam obter atendimento à saúde sem nenhuma restrição, mesmo tendo dado um depoimento negativo em relação à assistência recebida. Esses resultados possibilitaram fazer várias recomendações que, se incorporadas pelos profissionais e serviços de saúde, irão contribuir significativamente para a equidade entre os gêneros em termos de inclusão e atendimento nos projetos e programas de saúde, sobretudo nos grupos de educação para saúde oferecidos na assistência pré-natal.

\section{REFERÊNCIAS}

1. Villela W. O monitoramento da Plataforma de Ação da Conferência Internacional sobre População e Desenvolvimento no Brasil. Jornal da Rede Feminista de Saúde. 2004 Jun ; 26 (1-2). Hallado em: http://www.redesaude.org.br/Homepa-
ge/JornaldaRede/JR26/Jornal da Rede.26. pdf [Acceso en 2008 jun 02].

2. Santos OMB, Custódio ZAO. Encontro de gestantes do terceiro trimestre: uma experiência facilitadora para vivenciar o processo do nascimento. Texto Contexto-Enferm. 1997;6(1): 293-304.

3. Beretta MIR, Andrade AS. A Educação em saúde e a utilização do psicodrama em uma intervenção educativa com gestantes. Rev Min Enferm. 2004;8(1): 165252.

4. Nakano MAS, Shimo AKKS. Espaço destinado ao homem nos cursos de orientação pré-natal. Femina 1995;23(7): 65760.

5. Buist A, Morse CA, Durkin S. Men`s adjustiment to fatherhood: Implications for Obstetric Health Care. JOGNN 2002; 32(2):172-80.

6. Oliveira DL, Henstschel FBL, Espírito Santo, LC. Percepções e sentimentos de pais quanto a sua presença na sala de partos. Ver. Bras. Enferm. 1992;45(2/3):154164.

7. Montano RS, Nishimura SR, Bulgarelli STM. O Pré-natal. In: Spallicci MDB, Costa MTZ, Melleiro MM, organizadores. Gravidez e Nascimento. São Paulo: Editora da Universidade de São Paulo; 2002. p. 49-50.

8. Mullany BC, Becker S, Hindin MJ. The impact of including husbands in antenatal health education services on maternal health practices in urban Nepal: results from a randomized controlled trial. Health Education Research 2007;22(2):16676.

9. Schraiber LB, Gomes R, Couto MT. Homens e saúde na pauta da Saúde Coletiva. Ciência e Saúde Coletiva 2005;10(1):717.

10. Maldonado MT, Canella P. O trabalho grupal: estruturas e modelos. In: Recursos de relacionamento para profissionais de saúde. Rio de Janeiro: Reichmann e Afonso Editora; 2003. p. 280-309. 
11. Thiollent JM M. Metodologia da pesquisa-ação. $14^{\circ}$ ed. São Paulo: Cortez; 2005. p.16-22.

12. Hoga LAK, Reberte LM. Pesquisa-ação como estratégia para desenvolver grupos de gestantes. A experiência dos participantes. Rev. Esc. Enferm. USP 2007; 41(4):559-66.

13. Kvale S. From Speech to Text. In: An introduction to qualitative research interviewing. Thousand Oaks: Sage Publications; 1996. p. 160-175.

14. Polit DF, Beck CT, Hungler BP. Análise dos dados qualitativos. In: Fundamentos da pesquisa em enfermagem: métodos, avaliação e utilização. $5^{\mathrm{a}}$ ed. Porto Alegre: Artmed; 2004. pp. 355-77.

15. Janesick VJ. The dance of qualitative research design: metaphor, methodolatry, and meaning. In: Denzin NK, Lincoln YS. Strategies of qualitative inquiry. Thousand Oaks: Sage Publications; 1998. p. 35-55.

16. Morse JM. Designing funded qualitative research. In: Denzin NK, Lincoln YS. Strategies of qualitative inquiry. Thousand Oaks: Sage; 1998. p. 56-85.

17. Pinto CM, Basile ALO, Silva SF, Hoga LAK. O acompanhante no parto. Atividades desenvolvidas e avaliação da experiên- cia. Rev Min Enferm. 2003; 7(1):41-7.

18. Piccinini CA, Silva MR, Gonçalves TR, Lopes RS, Tudge J. O Envolvimento paterno durante a gestação. Psicol Reflex Crit 2004; 17(3):303-14.

19. Galastro EP, Fonseca RMGS. A participação do homem na saúde reprodutiva: o que pensam os profissionais de saúde. Rev. Esc. Enferm. USP 2007; 41(3):454-9

20. Fletcher RJ, Matthey S, Marley CG. Addresing depresion and anxiety among new fathers. Med J Aust 2006; 185(8): 461-63.

21. Arilha M. Homens, saúde reprodutiva e gênero: o desafio da inclusão. In: Giffin $\mathrm{K}$, Costa SH. Questões de saúde sexual e reprodutiva. Rio de Janeiro: Fiocruz; 1999. p. 455-67.

22. Finnbogadóttir H, Svalenius EC, Persson EK. Expectant first-time fathers experiences of pregnancy. Midwifery 2003; 19(2): 96-105.

23. Hoga LAK, Reberte LM. Técnicas corporais em grupo de gestantes: a experiência dos participantes. Ver. Bras. Enferm. 2006;59(3): 308-13.

24. Figueiredo W. Assistência à saúde dos homens. Um desafio para os serviços de atenção primária. Ciência \& Saúde Coletiva $2005 ; 10(1): 105-9$. 